\title{
A Low-Cost, Portable Optical Sensing System With Wireless Communication Compatible of Real-Time and Remote Detection of Dissolved Ammonia
}

\author{
Shijie DENG ${ }^{1 *}$, William DOHERTY ${ }^{2}$, Michael AP MCAULIFFE ${ }^{1}$, \\ Urszula SALAJ-KOSLA ${ }^{3}$, Liam LEWIS ${ }^{1}$, and Guillaume HUYET ${ }^{1,2}$ \\ ${ }^{1}$ Centre for Advanced Photonics \& Process Analysis, Cork Institute of Technology and Tyndall National Institute, Cork, \\ Ireland \\ ${ }^{2}$ Department of Physical Science, Cork Institute of Technology, Cork, Ireland \\ ${ }^{3}$ Department of Chemical and Environmental Science, University of Limerick, Limerick, Ireland \\ *Corresponding author: Shijie DENGＥ-mail: shijie.deng@cit.ie
}

\begin{abstract}
A low-cost and portable optical chemical sensor based ammonia sensing system that is capable of detecting dissolved ammonia up to $5 \mathrm{ppm}$ is presented. In the system, an optical chemical sensor is designed and fabricated for sensing dissolved ammonia concentrations. The sensor uses eosin as the fluorescence dye which is immobilized on the glass substrate by a gas-permeable protection layer. A compact module is developed to hold the optical components, and a battery powered micro-controller system is designed to read out and process the data measured. The system operates without the requirement of laboratory instruments that makes it cost effective and highly portable. Moreover, the calculated results in the system can be transmitted to a PC wirelessly, which allows the remote and real-time monitoring of dissolved ammonia.
\end{abstract}

Keywords: Ammonia sensing; optical chemical sensor; portable optical sensing system; remote sensing

Citation: Shijie DENG, William DOHERTY, Michael AP MCAULIFFE, Urszula SALAJ-KOSLA, Liam LEWIS, and Guillaume HUYET, "A Low-Cost, Portable Optical Sensing System With Wireless Communication Compatible of Real-Time and Remote Detection of Dissolved Ammonia," Photonic Sensors, 2016, 6(2): 107-114.

\section{Introduction}

Dissolved ammonia is an environmental toxicant that is especially problematic for aquatic organisms. Ammonia $\left(\mathrm{NH}_{3}\right)$ accumulates easily in aquatic systems because it is a natural byproduct of fish metabolism. All animals excrete some waste in the process of metabolizing food into the energy, nutrients, and proteins they use for survival and growth. For fish, the principal metabolic waste product is ammonia. Because it is continuously excreted and potentially lethal, successful aquaculture operations must therefore incorporate methods to detect and eliminate ammonia before it can accumulate and harm the aquatic life [1,2]. As a result, there is a real requirement to develop a cost effective and low maintenance system to allow for continuous monitoring of dissolved ammonia concentrations in aquatic environments.

Advances in optical chemical sensors including sensitive, highly selective, easy to miniaturize, electrical, and magnetic interference-free, reference electrode independent and operational in varied environments (e.g. air or liquid) have allowed them

Received: 30 September 2015 / Revised: 8 March 2016

(C) The Author(s) 2016. This article is published with open access at Springerlink.com

DOI: $10.1007 / \mathrm{s} 13320-016-0291-2$

Article type: Regular 
to be used in a wide range of applications such as medical application, environmental and pharmaceutical analysis, and process control [3-6]. In addition, the wide availability of the miniature photo-detectors and light sources and the broad usage of optical fibers make the optical chemical sensors very attractive for applications requiring portable and compact sensing solutions. In this work, to develop a portable ammonia sensing system, it is decided to design an optical chemical sensor for the detection of ammonia in the liquid.

A small number of optical chemical sensors based ammonia sensing systems have been developed for the detection of dissolved ammonia [7-10]. However, those systems require laboratory instruments to operate (e.g. laser source for incident light and a spectrometer or charge-coupled device (CCD)/color camera for sensor results readout). This makes them bulky and expensive, which limits the portability of the device.

In this work, an optical chemical sensor based ammonia sensing system that operates independently of laboratory instruments is developed. It is able to detect dissolved ammonia up to $5 \mathrm{ppm}$ and a lower detection limit of $0.1 \mathrm{ppm}$ is achieved with longer response time. In the system, an optical chemical sensor is developed and used for sensing dissolved ammonia. Eosin is used as the fluorescence dye which is immobilized on a glass substrate by a gas-permeable protection layer. A compact module is designed for housing the optical components, and a battery powered micro-controller based circuit is designed to control the incident light signal from the light-emitting diode (LED) and read out the fluorescence signal from the sensor. This makes the system highly portable and enhances its usefulness for compact applications. Moreover, the system allows users to transmit the measurement data to a PC through the wireless transceivers that makes it possible for real-time and remote monitoring.

\section{System description}

Figure 1 shows the block diagram of the ammonia sensing system developed, which consists of two main parts: A. the optical components and sensor module, which includes the optical ammonia sensor, an LED, a photo-detector, optical filters, and the holder for the components; B. the battery powered micro-controller based printed circuit board (PCB), which is used to modulate the light signal from the LED, process the fluorescence signal collected by the detector and transmit the data to a PC through the wireless transceivers.

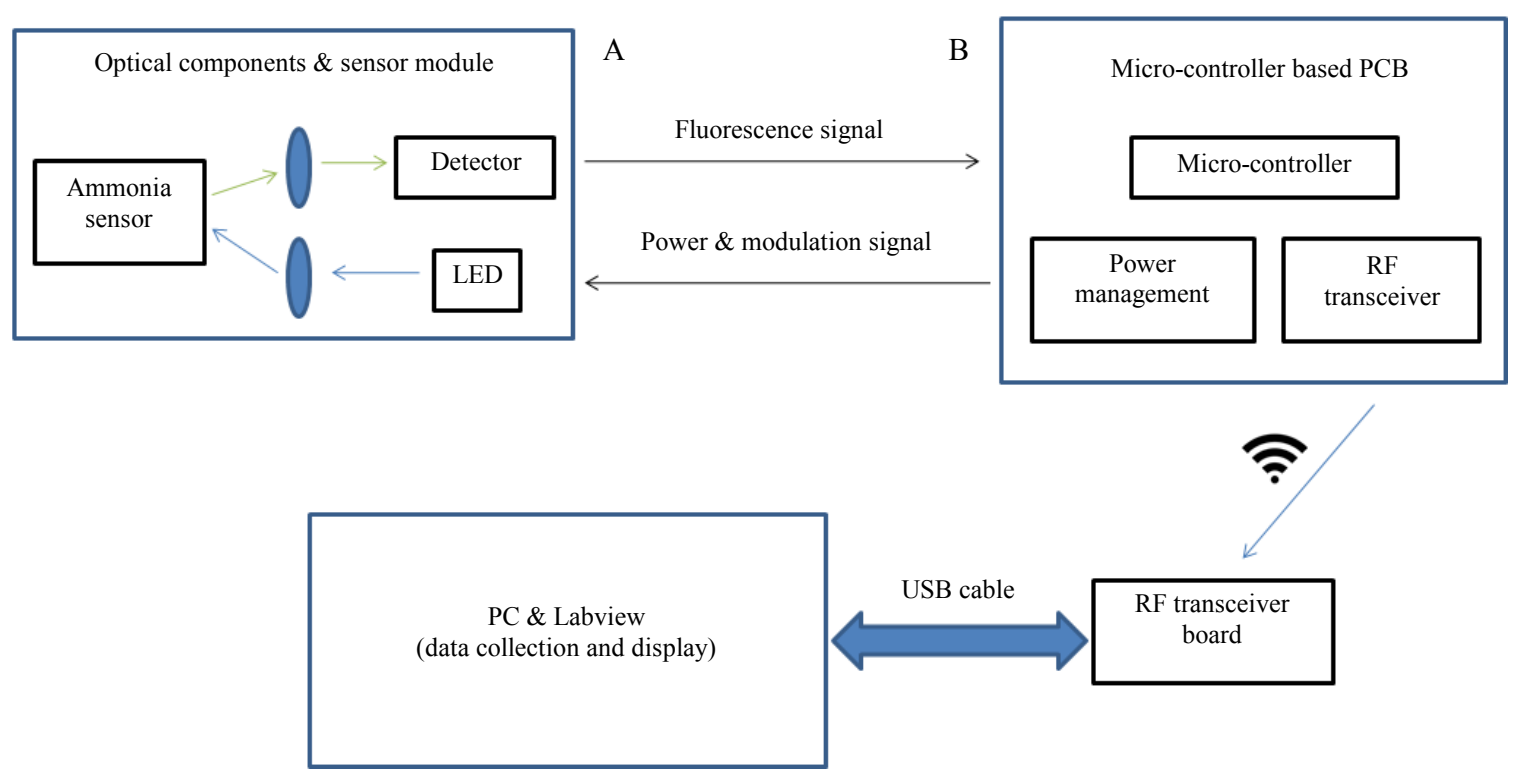

Fig. 1 Block diagram of the ammonia detection system. A and B highlight the optical and sensor module and the micro-controller based PCB, respectively. 


\subsection{Development of optical ammonia sensor}

Ammonia $\left(\mathrm{NH}_{3}\right)$ is an essential nutrient for plant and is not accessible in its molecular form. Bacteria can convert the dissolved ammonia to nitrite $\left(\mathrm{NO}_{2}^{-}\right)$ and nitrates $\left(\mathrm{NO}_{3}^{-}\right)$which can then be used by plants, a process known as "fixing". On interacting with water, ammonia is in equilibrium with ammonium ion and hydroxide ion as shown in (1):

$$
\mathrm{NH}_{3}+\mathrm{H}_{2} \mathrm{O} \leftrightharpoons \mathrm{NH}_{4}^{+}+\mathrm{OH}^{-} \text {. }
$$

The equilibrium lies to the right, meaning the vast majority of nitrogen exists in the ammonium ion form, rather than the ammonia form. In the ammonium form, it is quite harmless, and larger concentrations can be supported.

However, this equilibrium position is dependent on the $\mathrm{pH}$ of the system. Changes in $\mathrm{pH}$ can have a detrimental effect on the system. Given that the dissociation constant $K_{A}$ of a system is by definition constant and applying Le Châtelier's principle to the following equation, the effect of $\mathrm{pH}$ change can be seen. The dissociation constant of ammonium-ammonia system can be seen in (2) and (3):

$$
\begin{aligned}
& \mathrm{NH}_{4}^{+} \leftrightharpoons \mathrm{NH}_{3}+\mathrm{H}^{+} \\
& K_{A}=\frac{\left[\mathrm{NH}_{3}\right]\left[\mathrm{H}^{+}\right]}{\left[\mathrm{NH}_{4}^{+}\right]} .
\end{aligned}
$$

If the $\mathrm{pH}$ increases, effectively there are less ions. The system, which can be considered originally in equilibrium, has been disturbed, and will rearrange the distribution of concentration of components of the reaction so as to minimize the effects of the disturbance, i.e. $K_{A}$ must be kept constant. This is achieved by producing more ions, which also produces more $\mathrm{NH}_{3}$. Therefore, increasing the $\mathrm{pH}$ releases more $\mathrm{NH}_{3}$ into the system.

The ammonia sensor designed in this work is based on the change in optical properties associated with a change in $\mathrm{pH}$. To achieve this, a three-layer sensor is developed which consists of a solid inert support, a $\mathrm{pH}$ sensitive matrix, and a gas-permeable protection layer (see Fig.2). Supports used are glass microscope slides. The $\mathrm{pH}$ dye chosen is eosin which is a fluorescent dye with the advantage of having a low fluorescent state in low $\mathrm{pH}$ conditions and higher fluorescence in higher $\mathrm{pH}$ conditions $[\mathrm{pH}>3.0$, greater than the $\mathrm{pKa}$ (acid dissociation constant at logarithmic scale) of eosin]. It has an absorption maximum at $517 \mathrm{~nm}$ and an emission maximum at $538 \mathrm{~nm}$ [11].

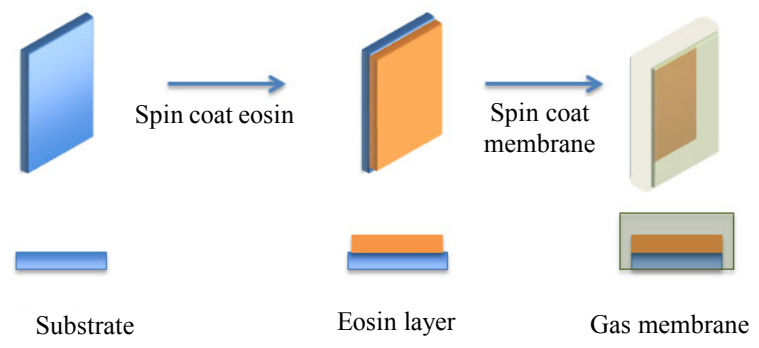

Fig. 2 Fabrication of the ammonia sensor.

The sensing film is comprised of eosin ( $1 \mathrm{mM})$, microcrystalline cellulose (MCC) $(5 \% \mathrm{w} / \mathrm{w})$, and methylsulfonic acid (MSA) $(0.7 \mu \mathrm{M})$ dissolved in a 99.5:1 acetone: water mixture. MCC is hygroscopic and will absorb moisture allowing a localized aqueous-type environment to form. The eosin is also absorbed in this aqueous-type environment and can respond to changes in the $\mathrm{pH}$ surrounding it. MSA $(\mathrm{pKa}=-1.9)$ is used to ensure that the local $\mathrm{pH}$ is below the pKa (2.9) of eosin. This protonates eosin and keeps it in the low-fluorescent state. Upon spin-coating $(600 \mathrm{rpm}, 50 \mathrm{~s})$, the solvent evaporates readily leaving a thin (70 micron) sensor film on the support. The sensor film is left to dry at room temperature for 24 hours and is then placed overnight in $0.7 \mu \mathrm{M}$ MSA solution to ensure protonation of the eosin dye.

To prevent the sensor film from sensing the bulk solution $\mathrm{pH}$, a gas permeable silicone layer $(25 \% \mathrm{w} / \mathrm{w}$ in $\mathrm{n}$-heptane) is spin coated $(1200 \mathrm{rpm}$, $50 \mathrm{~s})$ on top (100 micron nominal). Dissolved ammonia gas can diffuse through this layer, and ions and other liquid species cannot cross this gas-permeable membrane. In this manner, the sensor measures the local $\mathrm{pH}$ on the film side of the 
membrane and not the bulk solution $\mathrm{pH}$ outside the membrane.

One chemical pathway can be thought of as follows. This ammonia reacts with the water surrounding the eosin and MCC to form ammonium ions and hydroxide ions. This raises the local $\mathrm{pH}$ resulting in a change from the low-fluorescent to the high-fluorescent state.

$$
\frac{\text { bulk }}{\mathrm{NH}_{3(\mathrm{~g})} \text { diffuse }} \stackrel{\text { sensor }}{\mathrm{NH}_{3(\mathrm{~g})}+\mathrm{H}_{2} \mathrm{O}_{(\mathrm{l})} \rightleftharpoons \mathrm{NH}_{4(\text { (aq) }}^{+}+\mathrm{OH}_{(\mathrm{aq})}^{-}}
$$

Equation(4) shows the reaction scheme showing the interaction of dissolved ammonia in the bulk phase with the local $\mathrm{pH}$ and is illustrated in Fig. 3.

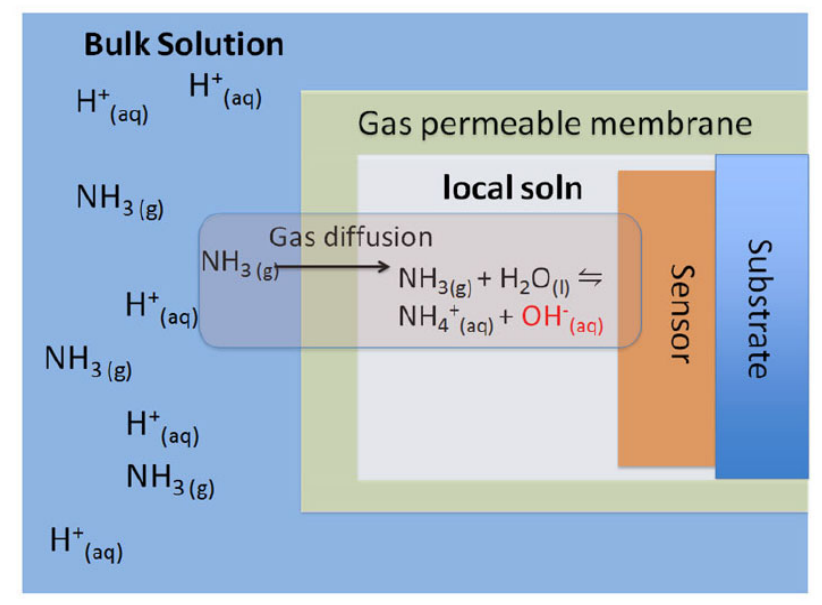

Fig. 3 Schematic of sensor mechanism illustrating (in boxed region) the diffusion of dissolved $\mathrm{NH}_{3(\mathrm{~g})}$ through the gas-permeable membrane and changing local $\mathrm{pH}$ (increase in $\mathrm{OH}$-concentration).

Another chemical pathway could be the direct deprotonation of eosin by dissolved ammonia. In either way of both chemical pathways, the overall effect is the same, and eosin is deprotonated to form the highly-fluoresecent anion.
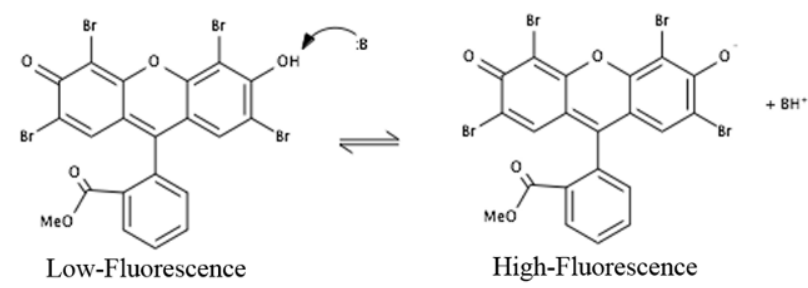

Fig. 4 Deprotonation of eosin. In the case of ammonia $\mathrm{B}=\mathrm{NH}_{3}$ and $\mathrm{BH}^{+}=\mathrm{NH}_{4}^{+}$. In the case of hydroxide ion pathway, simply substitute $\mathrm{B}$ with $\mathrm{OH}^{-}$and $\mathrm{BH}^{+}$with.

Standard solutions of ammonium ion to produce to required concentration of ammonia are prepared as follows.

Buffer solutions at $\mathrm{pH} 7$ are prepared using the 10:6 ratio of $0.01 \mathrm{M}$ sodium dihydrogen phosphate and $0.01 \mathrm{M}$ disodium hydrogen phosphate solutions.

Using the Hendersen-Hasselbalch equation the concentration of $\left[\mathrm{NH}_{3}\right]$ can be calculated:

$$
\left[\mathrm{NH}_{3}\right]=\left[\mathrm{NH}_{4}^{+}\right] \times 10^{(\mathrm{pH}-\mathrm{pKa})}
$$

or to obtain a given concentration of $\left[\mathrm{NH}_{3}\right]$, the concentration of $\left[\mathrm{NH}_{4}^{+}\right]$can be determined:

$$
\left[\mathrm{NH}_{4}^{+}\right]=\left[\mathrm{NH}_{3}\right] \times 10^{(\mathrm{pKa}-\mathrm{pH})}
$$

or given that the $\mathrm{pKa}$ is 9.24 and the $\mathrm{pH}$ is 7

$$
\left[\mathrm{NH}_{4}^{+}\right]=\left[\mathrm{NH}_{3}\right] \times 10^{2.24} \text {. }
$$

Table 1 outlines the concentrations of $\mathrm{NH}_{4} \mathrm{Cl}$ made up in the (phosphate) pH7 buffer solutions.

Table 1 Concentrations and masses of $\mathrm{NH}_{4} \mathrm{Cl}$ in $1 \mathrm{~L}$ of $\mathrm{pH} 7$ phosphate buffer solution to produce $1,2,3,5$ and $10 \mathrm{ppm} \mathrm{NH}_{3}$ solutions, using (5).

\begin{tabular}{cccc}
\hline $\begin{array}{c}{\left[\mathrm{NH}_{3}\right]} \\
(\mathrm{ppm})\end{array}$ & $\begin{array}{c}{\left[\mathrm{NH}_{3}\right]} \\
(\mathrm{mM})\end{array}$ & $\begin{array}{c}{\left[\mathrm{NH}_{4} \mathrm{Cl}\right]} \\
(\mathrm{mM})\end{array}$ & $\begin{array}{c}{\left[\mathrm{NH}_{4} \mathrm{Cl}\right]} \\
\left(\mathrm{mgL}^{-1}\right)\end{array}$ \\
\hline 1 & 0.059 & 10.20 & 545.8 \\
2 & 0.117 & 20.41 & 1091.6 \\
3 & 0.176 & 30.61 & 1637.4 \\
5 & 0.294 & 51.02 & 2729.0 \\
10 & 0.587 & 102.04 & 5458.1 \\
\hline
\end{tabular}

\subsection{Development of optics and electronics}

The optical components and sensor module designed is shown in Fig. 5(a). The size of the module is approximately $38 \mathrm{~mm} \times 38 \mathrm{~mm} \times 30 \mathrm{~mm}$.

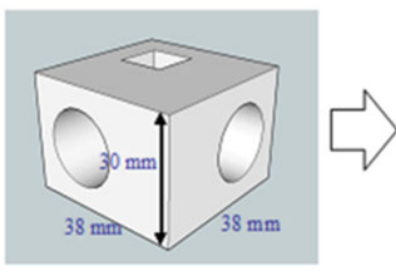

(a)

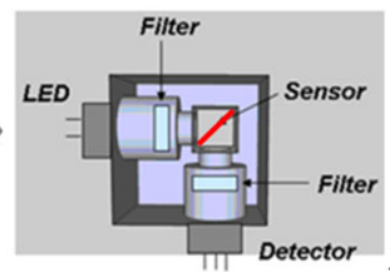

(b)
Fig. 5 Optical components and sensor module designed: (a) optical components and sensor holder and (b) schematic diagram of the optical components within module.

The incident light and emitted fluorescence paths are divided into 2 channels. The LED has a peak emission wavelength of $490 \mathrm{~nm}$, and the detector has a spectral range of $400 \mathrm{~nm}$ to $800 \mathrm{~nm}$. An optical band-pass filter $(475 \pm 25 \mathrm{~nm})$ is placed after the LED, and an optical long-pass filter $(530 \mathrm{~nm})$ is placed before the detector [Fig. 5(b)]. A 
hole $(13 \mathrm{~mm} \times 13 \mathrm{~mm} \times 30 \mathrm{~mm})$ in the module allows water to flow through to fill the region where the ammonia sensor is fixed across the diagonal. For this work, a cuvette is used with the sensor placed within a fixed volume of water and varying amounts of ammonia solution added to the water. The position of the ammonia sensor is fixed within the cuvette.
The electronics design is shown in Fig. 6. The main board is a micro-controller based PCB which consists of a micro-controller chip, power management circuit, A/D converter (ADC), Op-amp, and radio frequency (RF) transceiver. Another transceiver board is used to receive data sent from the main board and push the data to one of the serial COM ports on the PC through a USB cable.

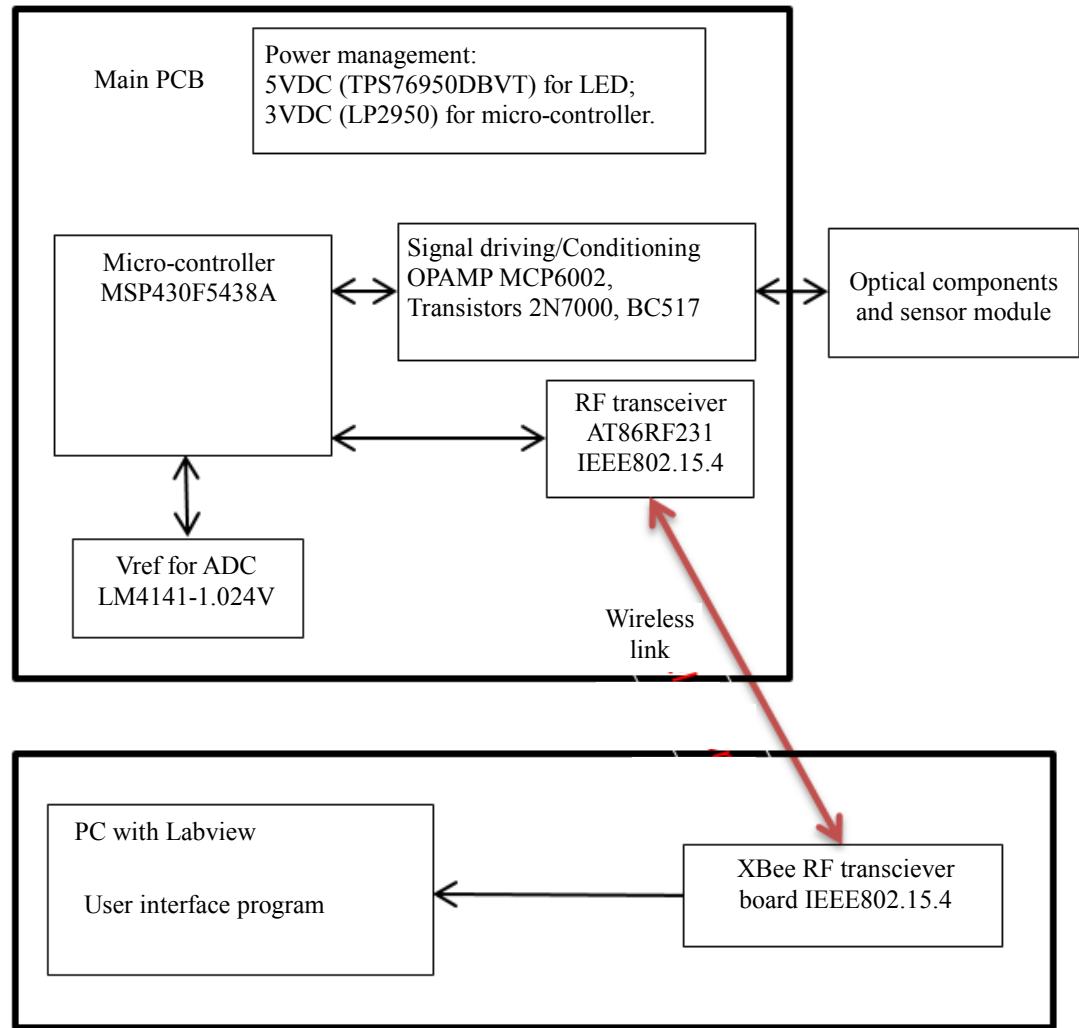

Fig. 6 Electronics design of the sensing system.


Wireless link



RF transceiver board

Fig. 7 Photograph of the ammonia sensing system developed. 
To avoid photo bleaching, the micro-controller is programmed to modulate the excitation light from the LED. The LED is on for 400 micro-seconds in every $15 \mathrm{~s}$. The photodiode detects the fluorescence signal emitted from the ammonia sensor, which is collected by the micro-controller through an $\mathrm{A} / \mathrm{D}$ converter. The micro-controller then calculates the peak-to-peak (pk-pk) amplitude and sends the results through an RF transceiver on the board to a second RF transceiver that transmits the data to a PC through a USB cable. The results can be displayed using a custom-written Labview routine on the PC.

\section{Experimental results}

A photograph of the system developed is shown in Fig. 7. The system is powered by 3 AA batteries, and the measurement dataare transmitted wirelessly to a PC using RF transceivers and processed using a custom-written Labview routine.

Figure 8 shows the response of the system for varies ammonia concentrations. During the measurement, the sensor is rinsed in a zero buffer $(0$ ppm of ammonia, pH7) and placed inside the cuvette, calibrated volumes of dissolved ammonia are pipetted into the cuvette. In the system, as there is an overlap between the LED's spectral output $(490 \mathrm{~nm})$ and the photo-detector's detection range $(400 \mathrm{~nm} \sim$ $800 \mathrm{~nm}$ ), the optical filters used do not block all the LED's light which is scattered to the photo-detector. This "leaked" excitation light from the LED is then picked up by the photo-detector that forms a baseline which is constant. To clearly demonstrate the changes of the fluorescence intensity emitted from the sensor for varies ammonia concentrations, the baseline has been deducted in the plots.

For the calibration, an average of the last 100 data points for each dissolved ammonia concentration are used to generate the calibration curve, as shown in Fig. 9. A three-parameter exponential decay function $\left(y=A_{1} \exp \left(-x / t_{1}\right)+y_{0}\right)$ is fitted to the sensor response which gives an accurate fit of $r^{2}=0.999$.

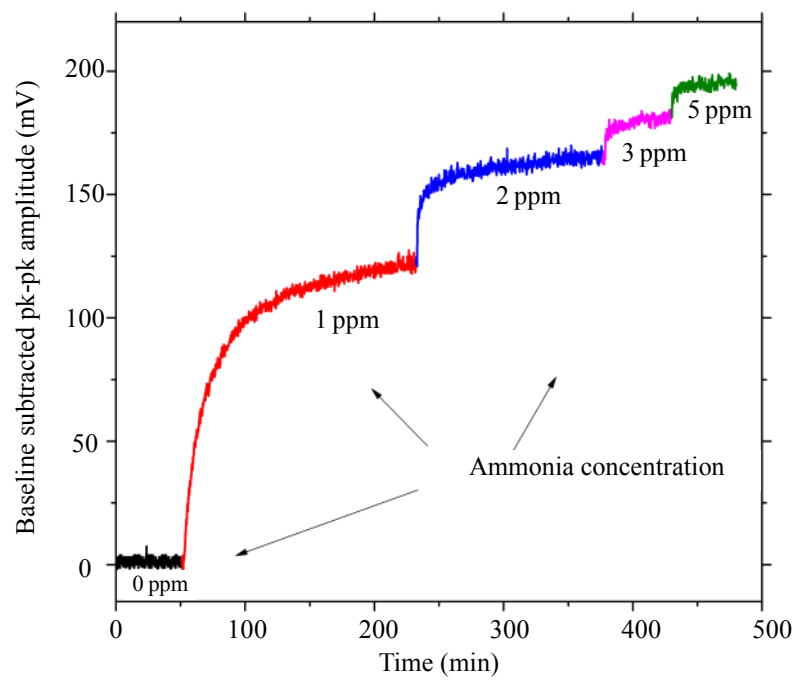

Fig. 8 Response curve of the system for various concentrations of dissolved ammonia in a buffer solution ( $\mathrm{pH} 7)$.



Fig. 9 Calibration curve, generated from the average of the last 100 data points of different dissolved ammonia concentrations. Error bars represent the standard deviation.

Figure 10 shows the response time of the sensor for a variety of dissolved ammonia concentrations. The typical response time from $0 \mathrm{ppm}$ to $0.1 \mathrm{ppm}$, $1 \mathrm{ppm}$, and $10 \mathrm{ppm}$ ammonia concentrations are 200 minutes, 80 minutes, and 20 minutes, respectively. This response is a convolution of diffusion process across the membrane and numbers of eosin molecules which have been deprotonated into the higher fluorescent state. As the numbers of fluorescent molecules are determined by the local $\mathrm{pH}$ of eosin, this exponential curve is expected. By 
varying the concentration of eosin and/or the amount of MSA, the response curve can be changed to give a stronger response or a more sensitive response. Larger concentrations of MSA would require larger concentrations of ammonia to affect the requisite change in local $\mathrm{pH}$ to enable a fluorescent state to form. Hence the applicable sensing range can be fine-tuned. Response time is mainly due to diffusion controlled process across the gas-permeable membrane. To achieve faster time, a thinner and structurally complete membrane is required.

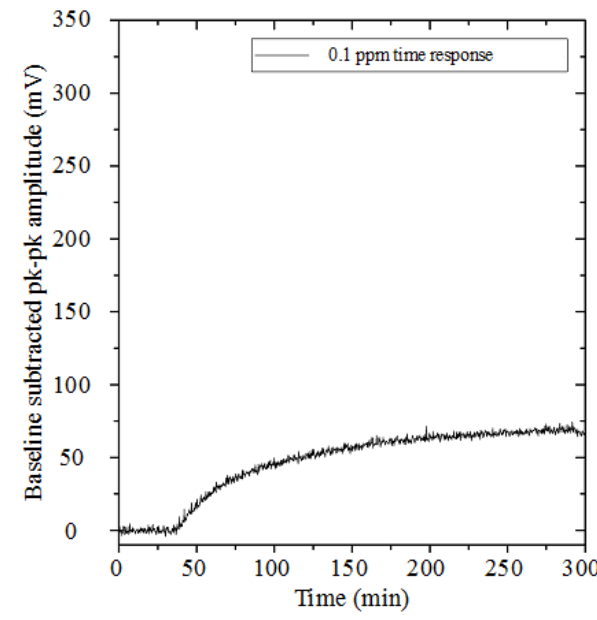

(a)



(b)

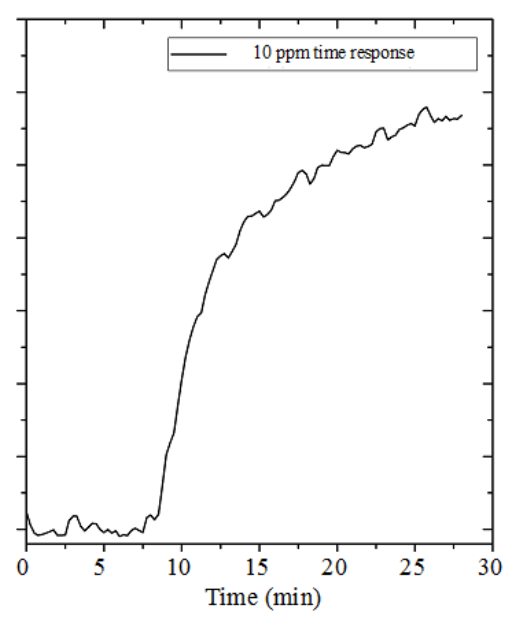

(c)

Fig. 10 Response time of the sensor for varies dissolved ammonia concentrations: (a) $0.1 \mathrm{ppm}$, (b) $1 \mathrm{ppm}$, and (c) $10 \mathrm{ppm}$.

\section{Conclusions}

In this work, an optical chemical sensor based ammonia detection system is developed, which is capable of detecting dissolved ammonia up to $5 \mathrm{ppm}$. To fabricate the optical chemical sensor in the system, eosin is used as the fluorescence dye which is immobilized on the glass substrate by a gas-permeable protection layer. The sensing system uses a compact module for housing the optical components and a battery powered micro-controller based circuit for the control of the incident light signal from the LED and readout of the fluorescence signal from the sensor. This allows the system to operate independently of the laboratory instruments that makes it low-cost and highly portable, and enables its usefulness for compact applications. Moreover, the system can communicate with a PC through wireless transceivers that makes it possible for real-time and remote monitoring of dissolved ammonia.

\section{Acknowledgment}

This work was supported by Enterprise Ireland (EI) and Science Foundation Ireland (SFI). The authors would like to thank Pat O'Leary from Faaltech Technologies Ltd and Jean-Michel Rubillon from Cork Institute of Technology for their support and help.

Open Access This article is distributed under the terms of the Creative Commons Attribution 4.0 International License (http://creativecommons.org/licenses/by/4.0/), which permits unrestricted use, distribution, and reproduction in any medium, provided you give appropriate credit to the original author(s) and the source, provide a link to the Creative Commons license, and indicate if changes were made.

\section{References}

[1] L. M. Nollet, Handbook of water analysis. Japan: Food Science and Technology, 2000.

[2] B. Timmer, W. Olthuis, and A. V. D. Berg, "Ammonia sensors and their applications-a review," Sensors and Actuators B: Chemical, 2005, 
107(2): 666-677.

[3] C. McDonagh, C. S. Burke, and B. D. MacCraith, "Optical chemical sensors," Chemical Reviews, 2008, 108(2): 400-422.

[4] O. S. Wolfbeis, "Fiber-optic chemical sensors and biosensors," Analytical Chemistry, 2008, 80(12): 4269-4283.

[5] A. R. Firooz, M. Movahedi, and A. A. Ensafi, "Selective and sensitive optical chemical sensor for the determination of $\mathrm{Hg}$ (II) ions based on tetrathia-12-crown-4 and chromoionophore I," Sensors and Actuators B: Chemical, 2012, 171-172(8): 492-498.

[6] Y. Wang, B. Li, L. Zhang, L. Liu, O. Zuo, and P. Li, "A highly selective regenerable optical sensor for detection of mercury (II) ion in water using organic-inorganic hybrid nanomaterials containing pyrene," New Journal of Chemistry, 2010, 34(9):
1946-1953.

[7] K. T. Lau, S. Edwards, and D. Diamond, "Solid-state ammonia sensor based on Berthelot's reaction," Sensors and Actuators B: Chemical, 2004, 98(1): $12-17$.

[8] S. Tao, L. Xu, and J. C. Fanguy, "Optical fiber ammonia sensing probes using reagent immobilized porous silica coating as transducers," Sensors and Actuators B: Chemical, 2006, 115(1): 158-163.

[9] T. Abel, B. Ungerböck, I. Klimant, and T. Mayr, "Fast responsive, optical trace level ammonia sensor for environmental monitoring," Chemistry Central Journal, 2012, 6(1): 21777-21778.

[10] K. Waich, T. Mayr, and I. Kilmant, "Fluorescence sensors for trace monitoring of dissolved ammonia," Talanta, 2008, 77(1): 66-72.

[11] R.W. Sabnis, Handbook of biological dyes and stains. New York: Wiley, 2010. 